\title{
SPLUNC1 reduces the inflammatory response of nasopharyngeal carcinoma cells infected with the EB virus by inhibiting the TLR9/NF-kB pathway
}

\author{
CHUNLIN OU $^{1 *}$, ZHENQIANG SUN $^{1,4^{*}}$, HAN ZHANG $^{1}$, WEI XIONG ${ }^{1-3}$, JIAN MA $^{1-3}$, \\ MING ZHOU ${ }^{1-3}$, JIANHONG LU ${ }^{1-3}$, ZHAOYANG ZENG ${ }^{1-3}$, XIANG BO ${ }^{1-3}$, \\ PAN CHEN ${ }^{1,2}$, GUIYUAN LI ${ }^{1-3}$, XIAYU LI ${ }^{1,3}$ and XIAOLING LI ${ }^{1-3}$ \\ ${ }^{1}$ Key Laboratory of Carcinogenesis of the Ministry of Health and Key Laboratory of Carcinogenesis and \\ Cancer Invasion of the Ministry of Education, Cancer Research Institute, Central South University; \\ ${ }^{2}$ Hunan Provincial Tumor Hospital and The Affiliated Tumor Hospital of Xiangya Medical School, \\ Central South University; ${ }^{3}$ Hunan Key Laboratory of Nonresolving Inflammation and Cancer, \\ The Third Xiangya Hospital, Central South University, Changsha, Hunan; \\ ${ }^{4}$ Department of Gastrointestinal Surgery, Affiliated Tumor Hospital, \\ Xinjiang Medical University, Urumqi, Xinjiang, P.R. China
}

Received December 11, 2014; Accepted February 19, 2015

DOI: $10.3892 /$ or.2015.3913

\begin{abstract}
Studies indicate that the natural immune-related protein short palate, lung, and nasal epithelium clone 1 (SPLUNC1) plays an antitumor role in nasopharyngeal epithelial tissue. However, the detailed mechanism of the tumor-suppressor effect of SPLUNC1 in the inflammatory microenvironment of Epstein-Barr virus (EBV)-associated nasopharyngeal carcinoma (NPC) remains elusive. The aim of the present study was to explore how SPLUNC1 reduces the inflammatory response of NPC cells infected with EBV by regulating the Toll-like receptor (TLR) $9 / \mathrm{NF}-\kappa \mathrm{B}$ signaling pathway. As detected by immunohistochemistry and western blotting, SPLUNC1 protein expression exhibited low or negative expression in the NPC epithelial samples/cells, while it demonstrated positive expression in normal nasopharyngeal epithelial tissues/cells; this pattern of expression was the contrary to that of TLR9. The poorly differentiated HNE2 cell
\end{abstract}

Correspondence to: Dr Xiayu Li or Professor Xiaoling Li, Hunan Provincial Tumor Hospital and The Affiliated Tumor Hospital of Xiangya Medical School, Key Laboratory of Carcinogenesis of the Ministry of Health and Key Laboratory of Carcinogenesis and Cancer Invasion of the Ministry of Education, Cancer Research Institute, Central South University, 283 Tongzipo Road, Changsha, Hunan 410013, P.R. China

E-mail: lixiayu@163.com

E-mail: lixiaoling@csu.edu.cn

*Contributed equally

Key words: short palate, lung, and nasal epithelium clone 1, Epstein-Barr virus, Toll-like receptor $9, \mathrm{NF}-\kappa \mathrm{B}$ signaling pathway, nasopharyngeal carcinoma line had the highest efficiency of transfer of infection with EBV by 'cell-to-cell' contact method. The group of EBV-infected HNE2 cells showed significantly higher activation of the expression of TLR9/NF- $\kappa \mathrm{B}$ signaling pathway-associated factors (TLR9, CD14, MyD88, IKK, P-IK $\beta \alpha$, P-NF- $\kappa \mathrm{B}$ and $\mathrm{NF}-\kappa \mathrm{B})$. The levels of inflammatory cytokines IL-6, IL-8, IL-1 $\beta$ and TNF- $\alpha$ in the HNE2 cell group after EBV infection were higher than these levels in the uninfected cell group $(\mathrm{P}<0.05)$; Meanwhile, after EBV infection, the expression levels of TLR9/NF- $\kappa \mathrm{B}$ pathway associated-protein and inflammatory cytokines IL-6, IL-8, IL- $1 \beta$ and TNF- $\alpha$ in the HNE2/SPLUNC1 cell group were lower than these levels in the HNE2/Vector cell group $(\mathrm{P}<0.05)$. After EBV-DNA direct transfection, cytokine mRNA expression levels of TLR9, IL-6, IL-8, IL-1 $\beta$ and TNF- $\alpha$ in the HNE2 cell group were significantly higher than these levels in the NP69 cell group $(\mathrm{P}<0.05)$. The expression levels of these cytokines in the HNE2/SPLUNC1 cell group were obviously lower than these levels in the HNE2/Vector cell group $(\mathrm{P}<0.05)$. These results suggest that EBV infection of NPC cells can activate the TLR9/ $\mathrm{NF}-\kappa \mathrm{B}$ signaling pathway, promote the release of inflammatory cytokines and consequently enhance the inflammatory response, while SPLUNC1 can weaken the inflammatory response induced by EBV infection in NPC cells through the regulation of the TLR9/NF- $\mathrm{B}$ signaling pathway and control of the tumor inflammatory microenvironment.

\section{Introduction}

Epstein-Barr virus (EBV) is a type of human herpes virus with a genome of double-stranded DNA and its natural host is only the human $(1,2)$. EBV has been reported to be closely associated with a variety of malignant lymphoma and epithelial cancers, particularly Burkitt's lymphoma and nasopharyngeal 
carcinoma (NPC). The tumorigenesis of NPC is a multifactor, multistep and multiple gene process, in which the relationship between EBV and NPC has been confirmed in most studies. Furthermore, in most poorly differentiated and undifferentiated squamous cell carcinoma the existence of EBV can be detected (3). By detecting the EBV genome in NPC tissues, it was shown that clusters of EBV tended to densely distribute in carcinoma nests, particularly in the center and periphery of tumor tissues, which suggests that NPC may originate from a mass of EBV-infected cancer cells (4). Due to the lack of the CD21 receptor, EBV cannot directly infect epithelial cells $(5,6)$, which is the main reason that EBV-stable transformational epithelial cell models and its tumorigenic animal models are scarce. Consequently, the mechanism of the tumorigenesis of EBV-associated NPC remains unclear.

The short palate, lung and nasal epithelium clone 1 (SPLUNC1), also called nasopharynx associated-specific gene (NASG), is a tissue-specific gene of the nasopharyngeal epithelium that has been cloned by suppression subtractive hybridization and cDNA microarray in our laboratory $(7,8)$. As a secretory protein, SPLUNC1 is specifically expressed in respiratory mucosal cells of the upper respiratory tract. Moreover, SPLUNC1 plays a vital role in mediating the defense response in the host respiratory tract to maintain normal physiological activity and exert antimicrobial and anti-inflammatory activity and tumor suppression. In recent years, some studies point out that SPLUNC1 has a close relationship with the inflammatory response. For example, SPLUNC1 was able to regulate Pseudomonas aeruginosa-induced lung inflammation in mice (9), and was found to be markedly downregulated in patients with chronic sinusitis (10). SPLUNC1 was found to modulate the inflammatory response to resist pulmonary inhaled particles by increasing leukocyte recruitment and phagocytic activity (11). However, the mechanism of how SPLUNC1 effects EBV-infected NPC has not been reported to date. In the present study, on the basis of two established types of cell infection, we confirmed that EBV infection of NPC cells activated the Toll-like receptor (TLR)9/NF- $\mathrm{KB}$ signaling pathway, promoted inflammatory cytokine release and consequently enhanced the inflammatory response; while SPLUNC1 weakened the inflammatory response induced by EBV infection in NPC cells through regulation of the TLR9/NF- $\mathrm{KB}$ signaling pathway and control of the tumor inflammatory microenvironment thus playing a regulatory role in tumorigenesis. Thus, the regulatory chain of EBV-SPLUNC1-TLR9/NF- $\kappa B$ inflammation was designed to illustrate the inflammatory regulation mechanism of NPC tumorigenesis.

\section{Materials and methods}

Ethics. The experiments were undertaken following the understanding and written consent of each subject. The study methodologies were approved by the Medical Ethics Committee of The Affiliated Tumor Hospital of Xinjiang Medical University (no. W201327) in accordance with the Code of Ethics of the World Medical Association (Declaration of Helsinki) for experiments involving humans.

Immunohistochemical assessment. Eight paraffin-embedded pathological biopsy samples of NPC were obtained from patients presenting with no other malignancies and inflammatory diseases (stage III, 48-73 years of age, females/males $3 / 5$, no preoperative chemoradiotherapy) and 8 paraffin-embedded pathological biopsy samples of normal nasopharyngeal tissues (healthy individuals).

The protein expression levels of SPLUNC1 and TLR9 were determined by EliVision ${ }^{\mathrm{TM}}$ two-step immunohistochemical method in the normal nasopharyngeal and NPC tissues. Briefly, paraffin-embedded sections (4- $\mu \mathrm{m})$ of the tissues were dewaxed at $60^{\circ} \mathrm{C}$ for $1 \mathrm{~h}$ and rehydrated in gradient alcohol. For antigen retrieval, the sections were incubated in sodium citrate buffer (0.01 M, pH 6.0) for $15 \mathrm{~min}$ in a microwave oven $(600 \mathrm{~W})$. After cooling to room temperature, endogenous peroxidase activity was blocked with $3 \% \mathrm{H}_{2} \mathrm{O}_{2}$ for $30 \mathrm{~min}$ at room temperature. The slides were incubated with normal goat serum in TBS (5\%) for $30 \mathrm{~min}$ to reduce non-specific staining and then incubated with mouse anti-human SPLUNC1 antibody (1:200) and mouse antihuman TLR9 antibody $(1: 1,000)$ (both from Abcam, Cambridge, UK) at $4^{\circ} \mathrm{C}$ overnight. After extensive washes with PBS, the slides were then incubated with polymerized HRP-anti-mouse/ rabbit IgG (EliVision ${ }^{\mathrm{TM}}$ Plus/HRP kit; Maxin, Fuzhou, China) according to the manufacturer's instructions. Color reaction was developed using liquid DAB (Maxin), and all slides were counterstained with hematoxylin.

Cell cultures and plasmids. HEK-293 cells stably transfected with the p2089 plasmid (293-EBV) were cultured in Dulbecco's modified Eagle's medium (DMEM) with $10 \%$ fetal calf serum (Therm, UK) (12). An immortalized normal nasopharyngeal epithelial cell line NP69 was cultured in keratinocyte serum-free medium (gifted by the Chinese University of Hong Kong) (13). The Raji cell line of human Burkitt's lymphoma is a EBV-infected and immortalized lymphocyte cell line (provided by the GSF-National Research Center for Environment and Health, Germany). Highly differentiated CNE1 cells, poorly differentiated HNE2 cells and undifferentiated 5-8F cells were all purchased from the Cancer Research Institute, Sun Yat-Sen University. HNE2 cells were stably transfected with SPLUNC1 (HNE2/ SPLUNC1 cells) and or transfected with the vector alone (HNE2/Vector cells), which were cultured in RPMI-1640 media supplemented with $10 \%$ fetal bovine serum (FBS) (both from Invitrogen, Carlsbad, CA, USA). All of the cells were placed in a $5 \% \mathrm{CO}_{2}$ atmosphere at $37^{\circ} \mathrm{C}$.

The coding region of the SPLUNC1 gene was inserted into the pEGFP vector as previously described (14). The plasmid p2089 (Maxi-EBV), which contained the complete EBV genome of the B95-8 strain was kindly provided by Professor W. Hammerschmidt (GSF-National Research Center for Environment and Health, Germany). Two eukaryotic expression vectors with the EBV-related BZLF1 and BALF4 genes (pcDNA3.1(+)/BZLF1 and pcDNA3.1(+)/BALF4) were constructed as previously described (15).

The established model of EBV-infected epithelial cells. Collection of green fluorescence protein-labeled EBV (GFP-EBV) was as follows. The viral genes BZLF1 and BALF4 in the pcDNA3.1(+) vector were transiently transfected into the 293-EBV cells $(12,16)$, and the GFP-EBV was released from the transfected cells into the supernatant due to 
expression of BZLF1 and BALF4 which was induced by lytic replication of the 293-EBV cells (17). After $72 \mathrm{~h}$, the supernatant was collected and filtered through a $0.45-\mathrm{mm}$ pore-size filter. Finally, the GFP-EBV was stored at $-80^{\circ} \mathrm{C}$.

EBV transferinfection. Through the cell-to-cell contact method in our laboratory as previously described $(12,18)$, three human NPC cell lines (highly differentiated CNE1, poorly differentiated HNE2 and undifferentiated 5-8F cells) were infected with recombinant GFP-EBV produced from the 293-EBV cells. Briefly, Raji cells were exposed to EBV produced from 293-EBV cells that were induced with the expression plasmids BZLF1 and BALF4 for $3 \mathrm{~h}$ at $4^{\circ} \mathrm{C}$. However, in the control group, Raji cells were directly treated at $4^{\circ} \mathrm{C}$ for $3 \mathrm{~h}$. The acceptor epithelial cells had been previously seeded in 2-ml wells $24 \mathrm{~h}$ prior to infection with $3 \times 10^{5}$ cells. After co-culture for up to $24 \mathrm{~h}$, the Raji cells were removed from the acceptors by washing. After co-culture for 48 h, GFP-positive cells were observed using green fluorescence microscopy, and the total RNA and protein were extracted from acceptor epithelial cells for further detection.

Human-specific type B CpG oligodeoxynucleotides (ODN) 2006 (5'-tcgtcgttttgtcgttttgtcgtt-3') were resuspended in endotoxin-free water and used as a positive control for TLR9 activation at the concentration as described in the literature (lowercase letters are phosphorothioate linkage) (42).

RNA extraction and real-time quantitative PCR ( $q R T-P C R)$. Total RNA was isolated from the cells using TRIzol reagent (Invitrogen). Reverse transcription reaction was performed using a Fermentas Revert Aid First Strand cDNA Synthesis kit (Fermentas, Burlington, ON, Canada), according to the manufacturer's instructions. qRT-PCR was performed using an iQ5 Multicolor Detection System (Bio-Rad, Hercules, CA, USA). The following program was used for qPCR: $95^{\circ} \mathrm{C}$ for $30 \mathrm{sec}$ followed by 40 cycles of $95^{\circ} \mathrm{C}$ for $5 \mathrm{sec}$ and then $60^{\circ} \mathrm{C}$ for $30 \mathrm{sec}$. The relative changes in expression were calculated using the $2^{-\Delta \Delta \mathrm{Ct}}$ (where $\mathrm{Ct}$ is threshold cycle) method. Three parallel repeats were performed for each sample in each experiment, and the results are expressed as the mean of three independent experiments. All of the qRT-PCR primers were designed by the online software Primer3 and synthesized by Sangon Biotech, China. Primer sequences for the qPCR were: TLR9 forward, 5'-CTGCCTTCCTACCCTGTGAG-3' and reverse, 5'-GGATGCGGTTGGAGGACAA-3; LMP1 forward, 5'-TGAACACCACCACGATGACT-3' and reverse, 5'-GTG CGCCTAGGTTTTGAGAG-3'; SPLUNC1 forward, 5'-CCC ATTCAAGGTCTTCTGGA-3' and reverse, 5'-CTGTAGTCC GTGGATCAGCA-3'; IL-6 forward, 5'-gaactcettctccacaa gcg-3' and reverse, 5'-tctgaagaggtgagtggctg-3'; IL-8 forward, 5'-tccaaacctttccaccccaa-3' and reverse, 5'-acttctccacaaccc tctgc-3'; IL-1 $\beta$ forward, 5'-AGCCTCGTGCTGTCGGACCC-3' and reverse, 5'-TCCAGCTGCAGGGTGGGTGT-3'; TNF- $\alpha$ forward, 5'-AGGGGCCACCACGCTCTTCT-3' and reverse, 5'-CATGCCGTTGGCCAGGAGGG-3'; GAPDH forward, 5'-ATCAAGATCATTGCTCCTCCTGAG-3' and reverse, 5'-CTGCTTGCTGATCCACATCTG-3'.

Western blotting. Firstly, the cells were resuspended in lysis buffer [1\% Nonidet P-40, 50 mM Tris-HCl, pH 7.5, $50 \mathrm{mM}$
NaF, 2 mM EDTA, 400 mM NaCl, 10\% glycerol plus Complete protease inhibitor mixture (Merck)]. Protein concentrations were determined using the bicinchoninic acid protein assay kit (Pierce Chemical Co., Rockford, IL, USA) by a Bradford assay, and cell lysates $(50 \mu \mathrm{g})$ were separated by $10 \%$ SDS-PAGE and transferred onto nitrocellulose membranes (all from Bio-Rad). After the membranes were blocked in Tris-buffered saline/Tween-20 (25 mM Tris-HCl, $150 \mathrm{mM}$ $\mathrm{NaCl}, \mathrm{pH} 7.5$ and $0.05 \%$ Tween-20) with $5 \%$ defatted milk for $1 \mathrm{~h}$ at $37^{\circ} \mathrm{C}$, the membranes were incubated overnight at $4^{\circ} \mathrm{C}$ with the primary antibodies in TBST with $5 \%$ defatted milk. After washing with TBST, the membranes were incubated with horseradish peroxidase-conjugated secondary antibodies (Santa Cruz Biotechnology) and visualized using the ECL detection system.

TLR9 mouse anti-human (h) and LMP1 mouse anti-h (Abcam); SPLUNC1 rabbit anti-h (Santa Cruz Biotechnology); CD14 rabbit anti-h/mouse (m) (Cell Signaling Technology, Danvers, MA, USA); MyD88 rabbit anti-h/m (Santa Cruz Biotechnology); IKK rabbit anti-h/m (Cell Signaling Technology); IK $\beta \alpha$ mouse anti-h/m, NF- $\kappa \mathrm{B}$ rabbit anti-h/m and p-NF-кB p65 (Ser 276) rabbit anti-h/m (all from Santa Cruz Biotechnology); GAPDH rabbit anti-h/m and $\beta$-actin mouse anti-h (Cell Signaling Technology) were used. HRP-labeled goat anti-rabbit, mouse and rabbit anti-goat secondary antibodies were purchased from Santa Cruz Biotechnology.

Virus purification and viral DNA isolation. The EBV concentrated particles were collected via 'the method of hunger'. After 7 days without replacing the medium, the B95-8 cells were completely splitting and EBV particles were fully released into the medium. Then, the virus particles were precipitated under the condition of $12,000 \mathrm{rpm}$ centrifugation for $2.5 \mathrm{~h}$ at $4{ }^{\circ} \mathrm{C}$ and then it was dissolved in $1 \mathrm{ml}$ fresh serum-free medium. The concentrated EBV-B95-8 suspension was collected and filtered through a $0.45-\mathrm{mm}$ pore-size filter, and then stored at $-80^{\circ} \mathrm{C}$. Viral dsDNA was purified from concentrated EBV-B95-8 suspension with a virus DNA extraction kit (Qiagen, Valencia, CA, USA) and the concentration was determined by spectrophotometry $(260 \mathrm{~nm})$. The EBV DNA or CpG was transfected into the cells (NP69, HNE2, HNE2/SPLUNC1 and HNE2/Vector) using Escort (Sigma-Aldrich, St. Louis, MO, USA) according to the manufacturer's instructions, and the total RNA was extracted for further measurement.

Statistical analysis. The differences between groups were tested using the Student's t-test or one-way analysis of variance (ANOVA). Calculations were performed using the SPSS 13.0 statistical software. $\mathrm{P}<0.05$ was considered to indicate a statistically significant result.

\section{Results}

Tissue immunohistochemical results and screening of high-efficient NPC cell lines infected by EBV. SPLUNC1 protein expression showed low or negative expression in the NPC epithelial samples, while it demonstrated positive expression in the normal nasopharyngeal epithelial tissues. TLR9 protein expression exhibited positive expression in the NPC epithelial samples, while it demonstrated low or negative 
A
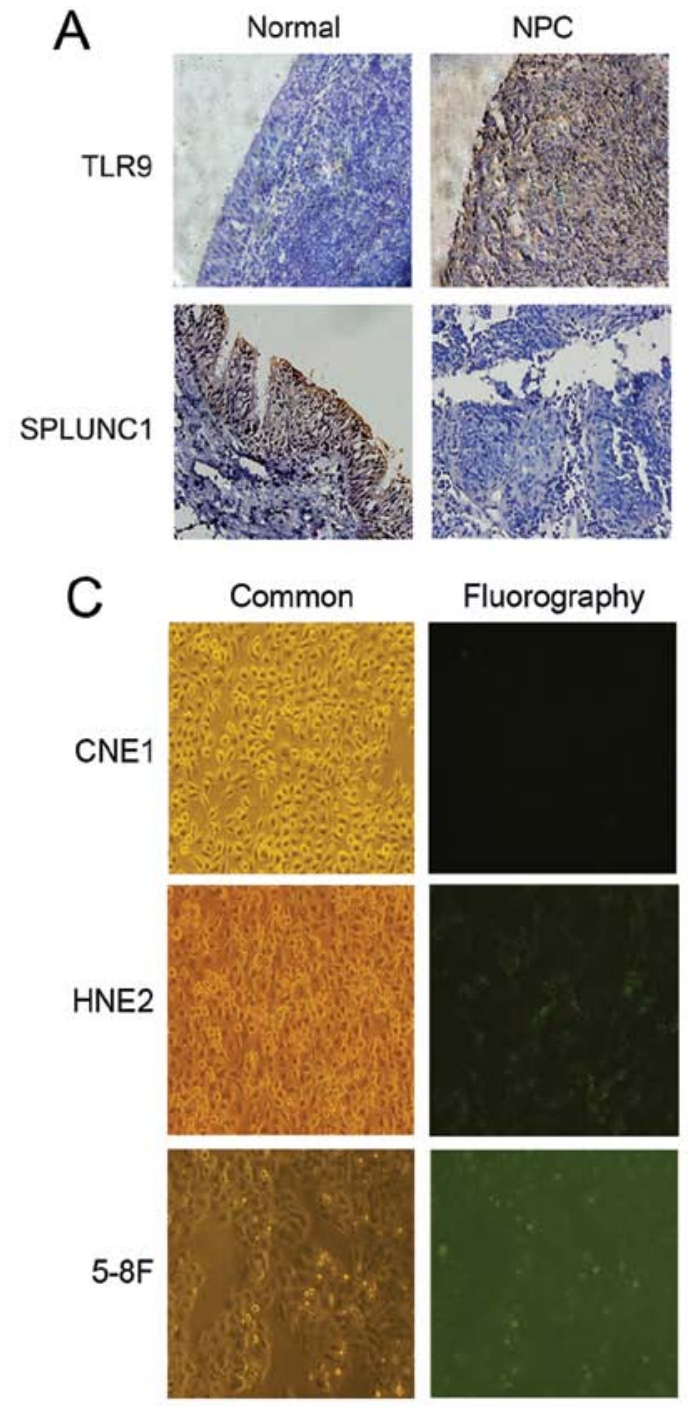

B

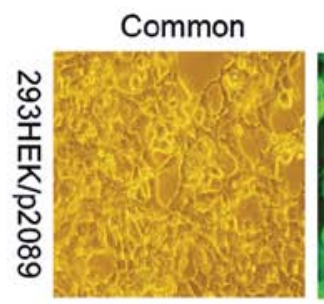

Fluorography

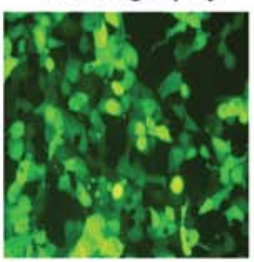

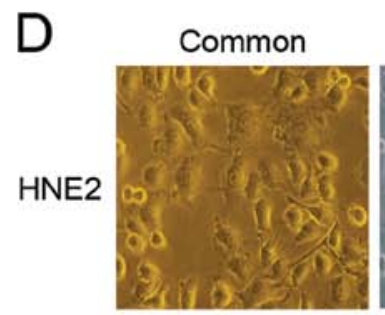
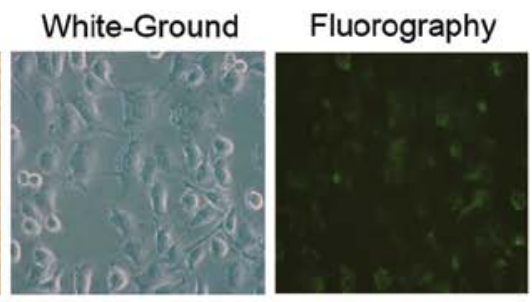

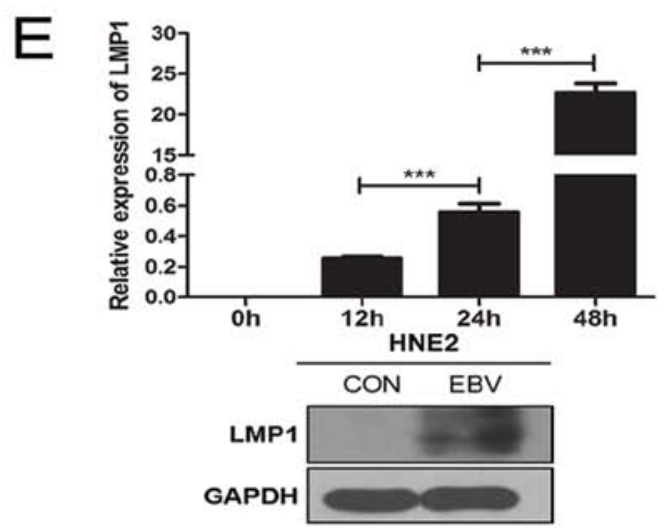

Figure 1. Tissue immunohistochemical analysis (magnification, x200) and establishment of the HNE2 cell line model of high-efficient transfer infection with EBV by 'cell-to-cell' method. (A) SPLUNC1 protein expression was weak or absent in the NPC epithelial samples, while it was positive in the normal nasopharyngeal epithelial tissues. TLR9 protein expression was positive in the NPC epithelial samples, while it was weak or absent in the normal nasopharyngeal epithelial tissues. (B) Fluorescence intensity of 293HEK/p2089 cells stably transfected with the BAC-EBV plasmid (p2089) which carries GFP (both, magnification, x100). (C) After a 48-h GFP-EBV infection, the appearance of the fluorescence intensity of the different cell lines is shown (magnification, x100). The poorly differentiated HNE2 NPC cell line showed the strongest fluorescence intensity, the undifferentiated nasopharyngeal carcinoma $5-8 \mathrm{~F}$ cell line was second, and the highly differentiated CNE1 NPC cell line showed weakest fluorescence intensity. (D) Common, white-ground and fluorography presentation of the HNE2 cell line. (E) LMP1 mRNA expression in the HNE2 cells was gradually increased at different time-points of 0,12,24 and $48 \mathrm{~h}$ after EBV infection. After a 48-h EBV infection, the protein expression of LMP1 in the HNE2 cell group was higher than that in the control group. Data represent means \pm SEM and are representative of three independent experiments; ${ }^{* * *} \mathrm{P}<0.001$ vs. adjacent time period. NPC, nasopharyngeal carcinoma; SPLUNC1, short palate, lung and nasal epithelium clone 1; EBV, Epstein-Barr virus; TLR, Toll-like receptor.

expression in the normal nasopharyngeal epithelial tissues (Fig. 1A). In the 293-EBV cells that stably expressed the plasmid p2089 (Maxi-EBV), green fluorescence (GFP) was observed by inverted fluorescence microscopy (Fig. 1B). After EBV infection of the NPC cell lines for $48 \mathrm{~h}$, the results showed that the poorly differentiated HNE2 NPC cell line showed the strongest fluorescence intensity, the undifferentiated NPC 5-8F cell line was second, and the highly differentiated CNE1 NPC cell line showed the weakest fluorescence intensity (Fig. 1C and D). LMP1 mRNA expression gradually increased at different time-points of $0,12,24$ and $48 \mathrm{~h}$ after EBV infection of the HNE2 cells, with statistically significant differences between adjacent time groups $(\mathrm{P}<0.001)$. After a 48-h EBV infection, the protein expression of LMP1 in the HNE2 cell group was much higher than that in the uninfected group (Fig. 1E). These results revealed that EBV infection efficiency of the HNE2 cells gradually increased over time.

EBV infection of HNE2 cells affects the TLR9/NF- $\kappa B$ signaling pathway. TLR3 is the natural ligand of EBV dsRNA. After a 48-h infection, the expression of TLR3 mRNA in the HNE2 cell group was higher than that in the uninfected group $(\mathrm{P}<0.001$, Fig. 2A). Expression of both TLR9 mRNA and SPLUNC1 mRNA in the HNE2 cells was gradually increased at different time-points of $0,12,24$ and $48 \mathrm{~h}$ after EBV infection (adjacent group, $\mathrm{P}<0.05$ ). After a 
A

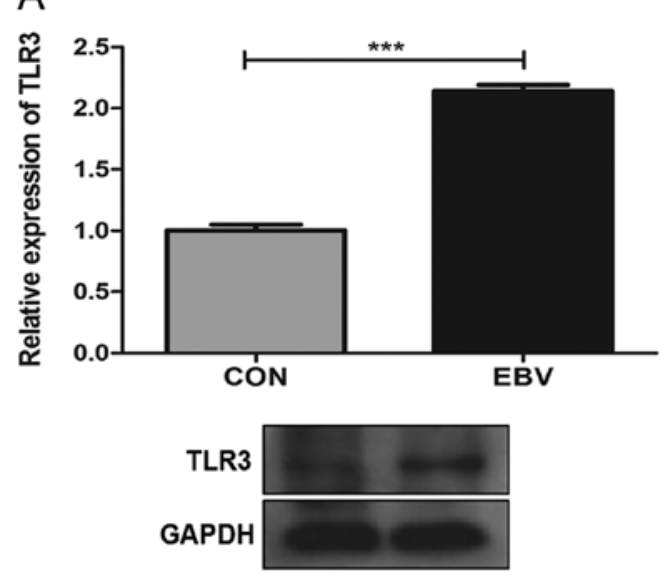

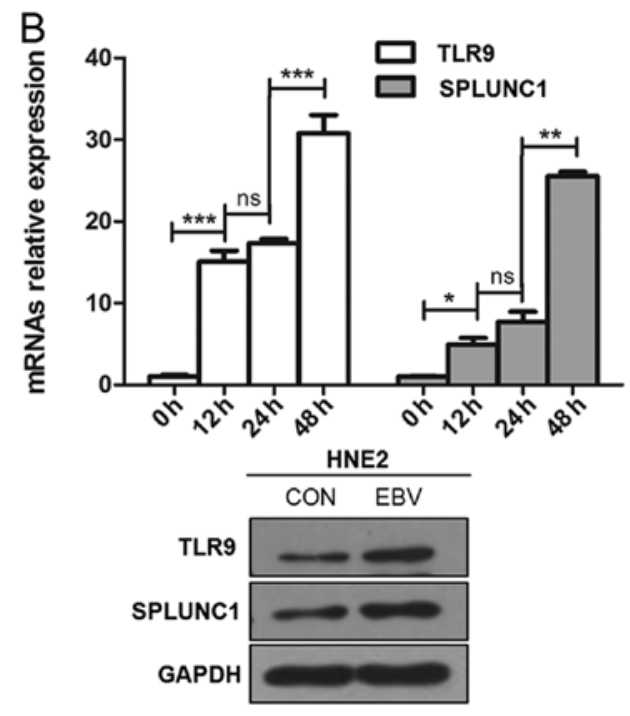

C

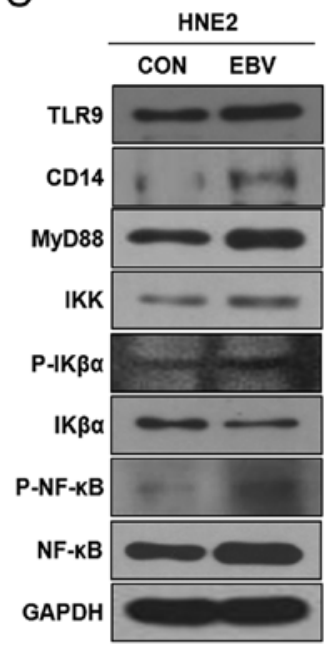

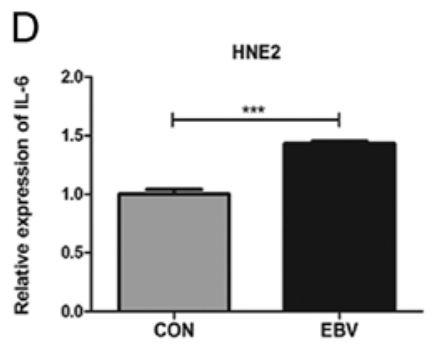

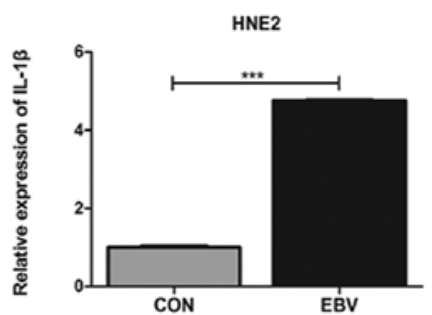

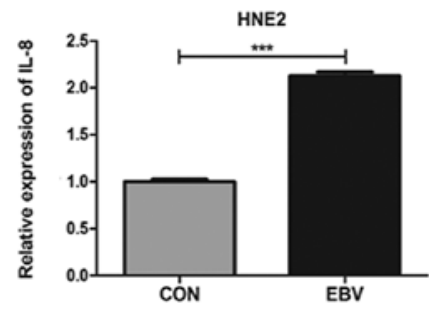

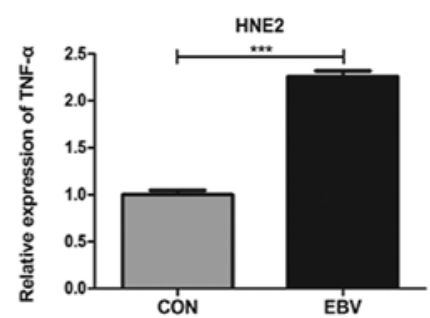

Figure 2. The effect of EBV infection of HNE2 cells on the TLR9/NF- $\mathrm{KB}$ signaling pathway. (A) After a 48-h infection, the expression of TLR3 mRNA in the HNE2 cell group was higher than that in the uninfected group. ${ }^{* * *} \mathrm{P}<0.001$ vs. control. (B) Expression of TLR9 mRNA and SPLUNC1 mRNA was gradually increased in the HNE2 cells at different time-points of 0,12, 24 and $48 \mathrm{~h}$ after EBV infection. After a 48-h infection, the protein expression levels of TLR9 and SPLUNC1 were higher in the HNE2 cell group than these levels in the uninfected group. ${ }^{* * * *} \mathrm{P}<0.001,{ }^{* * *} \mathrm{P}<0.01,{ }^{*} \mathrm{P}<0.05$ vs. adjacent time-points; ns, not significant. (C) After a 48-h infection, the protein expression levels of TLR9/NF- $\mathrm{BB}$ signaling pathway-associated cytokines (TLR9, CD14, MyD88, IKK, $\mathrm{P}-\mathrm{IK} \alpha, \mathrm{IK} \beta \alpha, \mathrm{P}-\mathrm{NF}-\mathrm{\kappa B}$ and NF- $\mathrm{KB}$ ) were higher in the HNE2 cell group than these levels in the uninfected group. (D) After a 48-h infection, mRNA expression levels of inflammatory cytokines IL-6, IL-8, IL-1 $\beta$ and TNF- $\alpha$ were higher in the HNE2 cell group than these levels in the uninfected group. ${ }^{* * *} \mathrm{P}<0.001$ vs. control. Data represent means \pm SEM and are representative of three independent experiments. SPLUNC1, short palate, lung and nasal epithelium clone 1; EBV, Epstein-Barr virus; TLR, Toll-like receptor.

48-h infection, protein expression of TLR9 and SPLUNC1 in the HNE2 cell group was higher than that in the uninfected group (Fig. 2B). After a 48-h infection, the protein expression levels of TLR9/NF- $\kappa \mathrm{B}$ signaling pathway-associated cytokines (TLR9, CD14, MyD88, IKK, P-IK $\alpha$, IK $\beta \alpha$, P-NF- $k B$ and NF- $\kappa B$ ) in the HNE2 cell group were higher than these levels in the uninfected group (Fig. 2C). Meanwhile, after a 48-h infection, mRNA expression levels of inflammatory cytokines IL-6, IL-8, IL- $1 \beta$ and TNF- $\alpha$ in the HNE2 cell group were higher than these levels in the uninfected group $(\mathrm{P}<0.05$, Fig. 2D). These results revealed that EBV infection of NPC cells can activate the TLR9/NF- $\kappa B$ signaling pathway, promote the release of inflammatory cytokines and consequently enhance the inflammatory response.
SPLUNC1 regulatory effect on the inflammatory reaction induced by EBV transferred infection of HNE2 cells. After a 48-h infection, the protein expression of not only SPLUNC1 but also all TLR9/NF- $\mathrm{BB}$ signaling pathway-associated cytokines in the HNE2/SPLUNC1 cell group (transient transfection) were higher than these levels in the HNE2/Vector cell group (Fig. 3A). SPLUNC1 mRNA and protein expression levels in the HNE2/SPLUNC1 cell group (stable transfection) were significantly higher than these levels in the HNE2/Vector cell group. In addition, TLR9 mRNA and protein expression levels in the HNE2/SPLUNC1 cell group (stable transfection) were lower than these levels in the HNE2/Vector cell group (Fig. 3B). After a 48-h infection, the protein expression levels of all TLR9/NF- $\kappa B$ signaling pathway-associated cytokines 
A

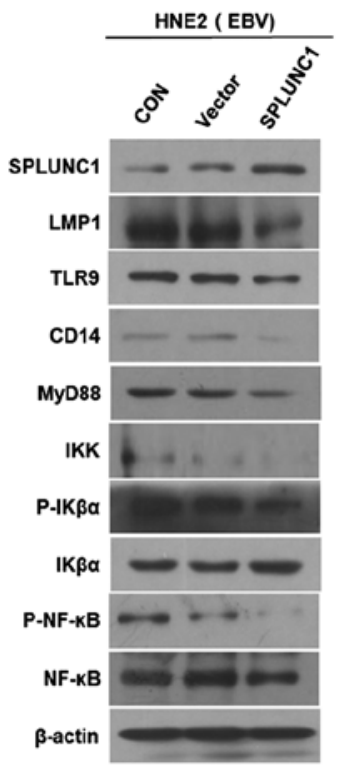

B
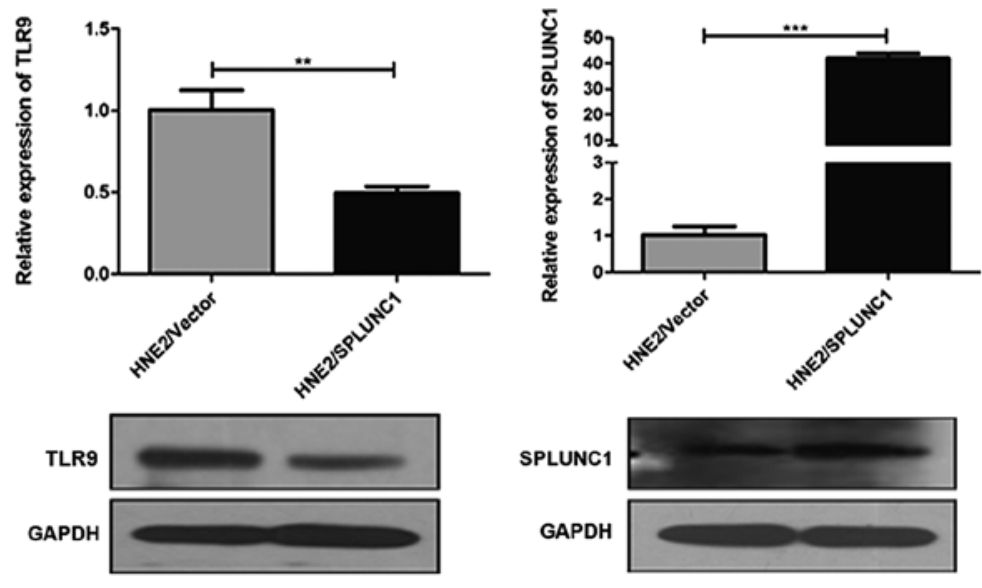

C

D
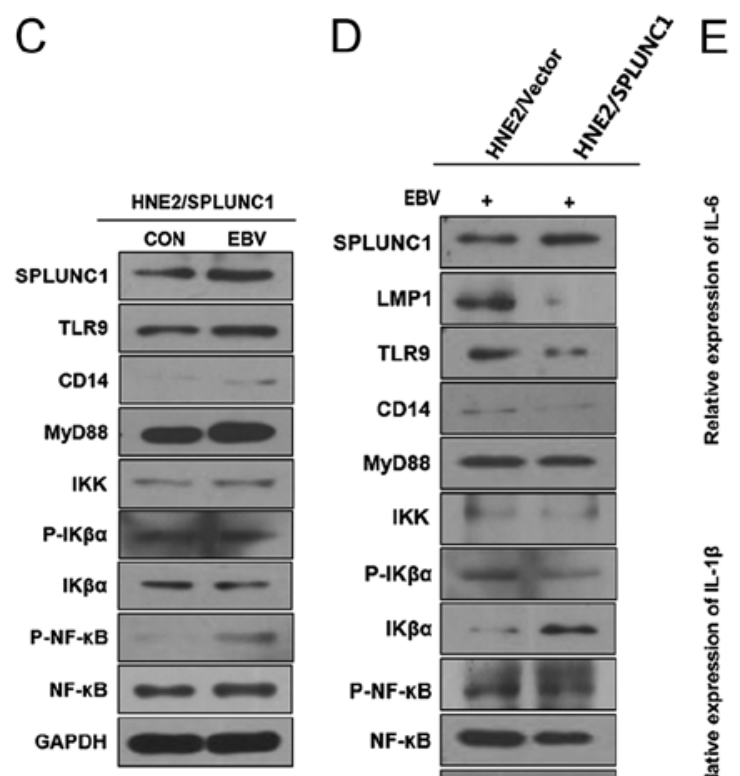

$E$
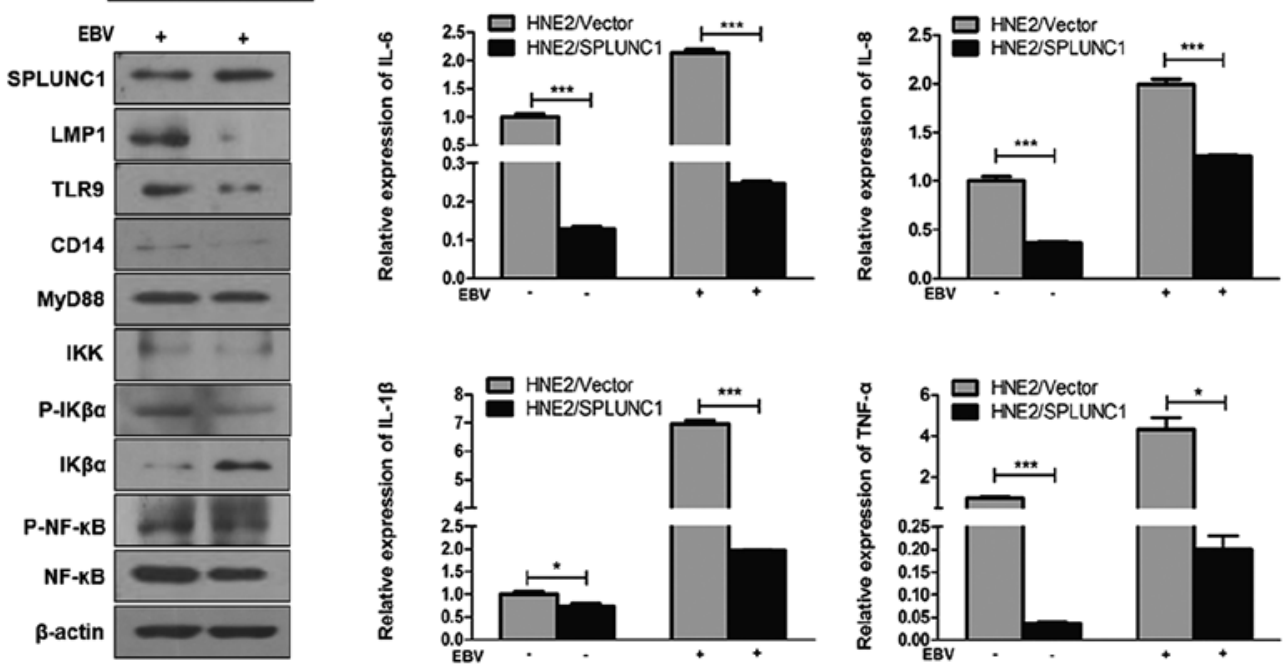

Figure 3. The regulatory effect of SPLUNC1 on the inflammatory reaction induced by EBV transferred infection of HNE2 cells. (A) After a 48-h infection, the protein expression levels of SPLUNC1 and all TLR9/NF-KB signaling pathway-associated cytokines were higher in the HNE2/SPLUNC1 cell group (transient transfection) than these levels in the HNE2/Vector cell group. (B) SPLUNC1 mRNA and protein expression levels were significantly higher in the HNE2/SPLUNC1 cell group (stable transfection) than these levels in the HNE2/Vector cell group. TLR9 mRNA and protein expression levels were lower in the HNE2/SPLUNC1 cell group (stable transfection) than these levels in the HNE2/Vector cell group. ${ }^{* * *} \mathrm{P}<0.001,{ }^{* *} \mathrm{P}<0.01$ vs. the HNE2/Vector cell group. (C) After a 48-h infection, the protein expression of all TLR9/NF-kB signaling pathway-associated cytokines but also SPLUNC1 were higher in the HNE2/ NASG cell group than these levels in the uninfected cell group. IK $\beta \alpha$ protein expression had a contrasting trend. (D) After a 48-h infection, the protein expression levels of all TLR9/NF-kB signaling pathway-associated cytokines were lower in the HNE2/SPLUNC1 cell group than these levels in the HNE2/ vector cell group. IK $\beta \alpha$ protein expression had a contrasting trend. (E) After 48-h infection, the mRNA expression levels of inflammatory cytokines IL-6, IL-8, IL-1 $\beta$ and TNF- $\alpha$ were significantly higher in the HNE2 cell group than these levels in the uninfected cell group, while the mRNA expression levels of these inflammatory cytokines were lower in the HNE2/SPLUNC1 cell group than these levels in the HNE2/Vector cell group. ${ }^{* * *} \mathrm{P}<0.001,{ }^{*} \mathrm{P}<0.05$. Data represent means \pm SEM and are representative of three independent experiments. SPLUNC1, short palate, lung and nasal epithelium clone 1; EBV, Epstein-Barr virus; TLR, Toll-like receptor.

but also SPLUNC1 were higher in the HNE2/SPLUNC1 cell group than these levels in the uninfected cell group. On the contrary IK $\beta \alpha$ protein expression had a contrasting trend (Fig. 3C). After a 48-h infection, the protein expression levels of all TLR9/NF- $\mathrm{KB}$ signaling pathway-associated cytokines were lower in the HNE2/SPLUNC1 cell group than these levels in the HNE2/Vector cell group; the protein expression of IK $\beta \alpha$ showed a contrasting trend (Fig. 3D). The mRNA expression levels of inflammatory cytokines IL-6, IL-8, IL-1 $\beta$ and TNF- $\alpha$ after a 48 -h infection were significantly higher in the HNE2 cell group than these levels in the uninfected cell group. Meanwhile, the mRNA expression levels of these 
A
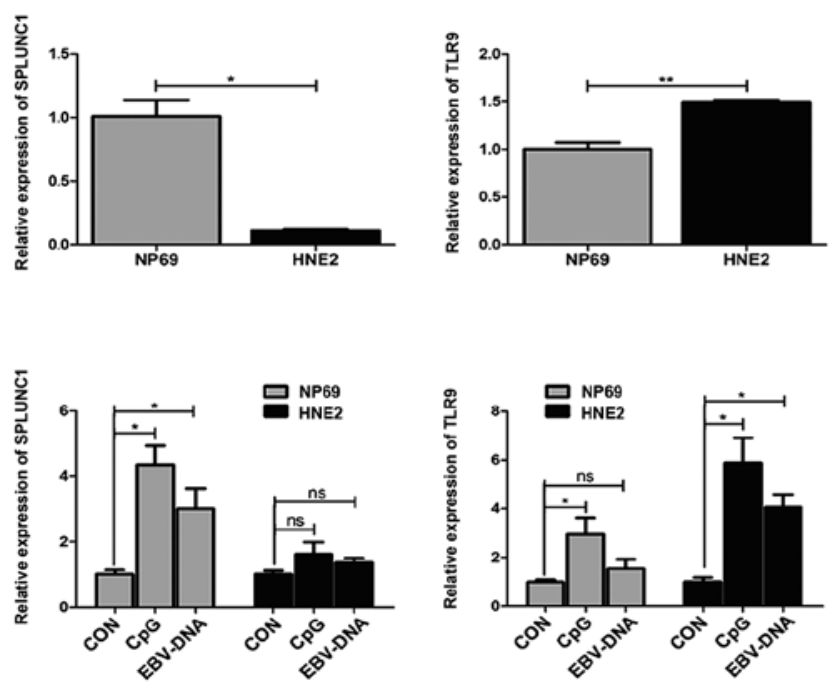

C
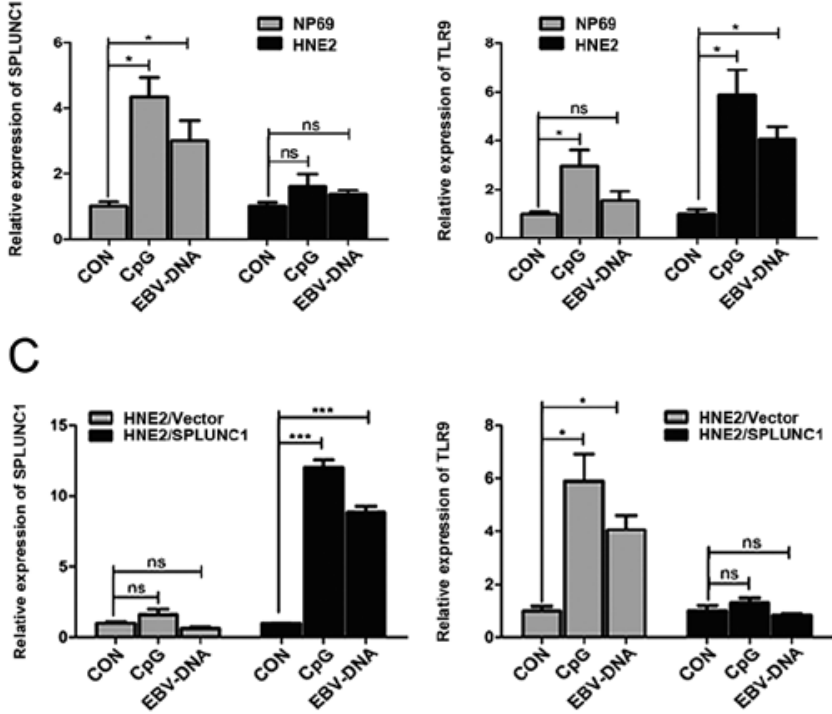

B
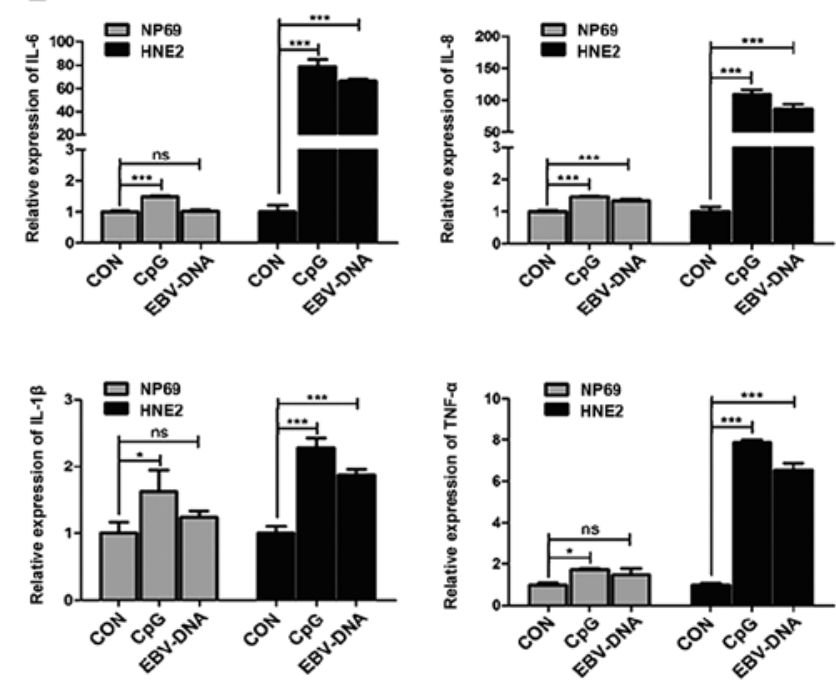

D
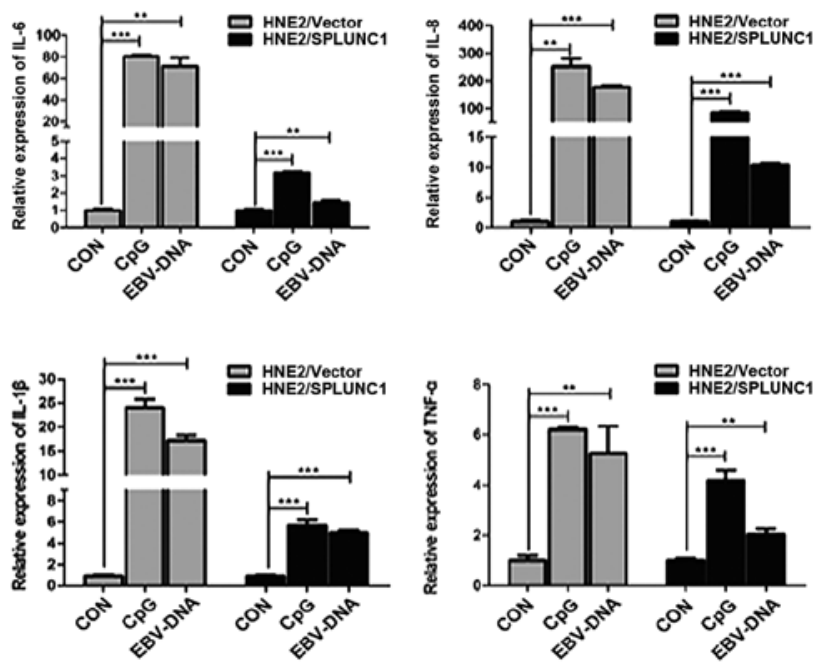

Figure 4. Regulatory effect of SPLUNC1 on the inflammatory reaction induced by EBV-DNA direct infection of HNE2 cells. (A) SPLUNC1 mRNA expression was lower in the HNE2 cell group than that in the NP69 cell group. TLR9 mRNA expression was slightly higher in the HNE2 cell group than that in the NP69 cell group. After a 48-h EBV-DNA direct transfection, TLR9 mRNA expression in the HNE2 and NP69 cell groups was increased, but it was increased more obviously in the HNE2 cell group. ${ }^{* *} \mathrm{P}<0.01,{ }^{*} \mathrm{P}<0.05$. ns, not significant. (B) After a 48 -h direct transfection, the mRNA expression levels of inflammatory cytokines IL-6, IL-8, IL-1 $\beta$ and TNF- $\alpha$ were increased more significantly in the HNE2 cell group than these levels in the NP69 cell group. ${ }^{* * * *} \mathrm{P}<0.001,{ }^{*} \mathrm{P}<0.05$. ns, not significant. (C) After a 48-h direct transfection in both groups, TLR9 mRNA expression in the HNE2/SPLUNC1 cell group was not significantly changed, while its mRNA expression in the HNE2/Vector cell group was significantly increased. ${ }^{* * *} \mathrm{P}<0.001,{ }^{*} \mathrm{P}<0.05$. ns, not significant. (D) After a 48-h direct transfection in both groups, the mRNA expression levels of inflammatory cytokines IL-6, IL-8, IL-1 $\beta$ and TNF- $\alpha$ were increased less significantly in the HNE2/SPLUNC1 cell group than these levels in HNE2/Vector cell group. ${ }^{* * *} \mathrm{P}<0.001,{ }^{* *} \mathrm{P}<0.01$. Data represent means \pm SEM and are representative of three independent experiments. SPLUNC1, short palate, lung and nasal epithelium clone 1; EBV, Epstein-Barr virus; TLR, Toll-like receptor

inflammatory cytokines in the HNE2/SPLUNC1 cell group were lower than these levels in the HNE2/Vector cell group $(\mathrm{P}<0.05$, Fig. 3E).

SPLUNC1 regulatory effect on the inflammatory reaction induced by EBV-DNA direct infection of HNE2 cells. SPLUNC1 mRNA expression in the HNE2 cell group was lower than that in the NP69 cell group $(\mathrm{P}<0.05)$, while TLR9 mRNA expression was slightly higher than that in the NP69 cell group $(\mathrm{P}>0.05)$; After a direct 48 -h transfection of EBV-DNA, TLR9 mRNA expression in both the HNE2 and NP69 cell groups was increased, but it was increased more obviously in the HNE2 cell group (Fig. 4A). After a direct 48-h transfection, the mRNA expression levels of inflammatory cytokines IL- 6, IL- 8 , IL- $1 \beta$ and TNF- $\alpha$ in the HNE2 cell group were increased more significantly than these levels in the NP69 cell group (Fig. 4B). After a direct 48-h transfection in both groups, TLR9 mRNA expression in the HNE2/SPLUNC1 cell group was not significantly changed $(\mathrm{P}>0.05)$, while its mRNA expression in the HNE2/Vector cell group was significantly increased $(\mathrm{P}<0.05$, Fig. $4 \mathrm{C})$. After a direct 48 -h transfection in both groups, the mRNA expression levels of inflammatory cytokines IL-6, IL-8, IL- $1 \beta$ and TNF- $\alpha$ were increased less significantly in the 
HNE2/SPLUNC1 cell group than the expression levels in the HNE2/Vector cell group (Fig. 4D).

\section{Discussion}

The present study was the first to screen the NPC cell line with susceptibility to EBV and demonstrate that a poorly differentiated HNE2 cell line was more susceptible to EBV than the other cell lines. The results were consistent with a study by Wang et al (19) who found that the vast majority of poorly differentiated or undifferentiated NPC samples exhibited EBV-DNA infection. One reason may be that poorly differentiated NPC cell lines have a more rapid proliferative ability with the status of cell division activity, which causes EBV to be embedded more easily into the DNA of NPC cells through a series of processes and leads to EBV infection phenomenon in these cells.

A sign of effective EBV infection is that EBV-DNA transfers into the host cells and promotes genome replication and transcription (20). In addition, EBV infection may occur in the nasopharyngeal inflammatory stage and result in enhanced membrane permeability of nasopharyngeal epithelial cells. In the present study, after HNE2 cells were infected, the natural ligand TLR9 with the combination ability of EBV nonmethylated nucleotide sequence was activated, its expression quantity increased, the levels of cytokines of the TLR9/NF- $\mathrm{BB}$ pathway were upregulated and expression levels of inflammatory factors IL-6, IL- 8 , IL-1 $\beta$ and TNF- $\alpha$ were increased. We believe that when EBV infects HNE2 cells, a series of cascade reactions in molecules such as CD14 and MyD88 occurs, and cytokine IK $\beta \alpha$, an NF- $\kappa B$ inhibitory factor, is phosphorylated by the IKK kinase complex, which relieves the inhibition of

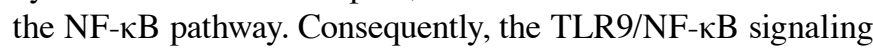
pathway is activated and inflammatory cytokines IL-6, IL-8, IL-1 $\beta$ and TNF- $\alpha$ are upregulated. Studies (21-23) have reported that cytokine NF- $\mathrm{kB}$ is a key node protein of the inflammatory response and resistance to apoptosis and its high expression and overactivity are one of the main characteristics of inflammationassociated cancer. Moreover, cytokine NF- $\mathrm{KB}$ transfers into the nucleus after activation, leading to the induction of the secretion of numerous inflammatory cytokines such as IL- 6 , IL-8, IL-1 $\beta$ and TNF- $\alpha$. Furthermore, the immunosuppression induced by accumulation of these inflammatory factors greatly increases the risk of inflammation-associated carcinogenesis $(24,25)$.

TLRs are a family of receptors that play a critical role in mounting an immune response against microbial pathogens. TLRs are the pathogen-associated molecular pattern recognition receptors linking innate and specific immunity (26-29). The interaction of these motifs with the TLRs triggers a cascade of signaling events which stimulate the products of pro-inflammatory cytokines and chemokines to respond to the invading pathogen. As a member of the TLR family, TLR9 expression is noted in many malignancies, such as lung and cervical cancer and NPC (30-33). TLR9 activation can induce high expression of cytokines and chemokines, cause tumorinflammatory microenvironment formation and promote the occurrence and development of malignancies $(34,35)$. Baumann et al (36) found that the CD14 molecule plays an essential role in induction of the inflammatory response following TLR9/NF- $\kappa \mathrm{B}$ pathway activation. In the present study, in the EBV-infected HNE2 cells, the expression of TLR9/NF- $\kappa$ B pathway-associated factors was significantly upregulated. Meanwhile, IK $\beta \alpha$ molecule expression was downregulated. Inflammatory cytokine expression levels of IL-6, IL-8, IL-1 $\beta$ and TNF- $\alpha$ were correspondingly and highly increased. The phenomenon suggests that the TLR9/NF- $\mathrm{KB}$ pathway plays an important role in the mediated inflammatory reaction induced by the EBV infection of HNE2 cells.

SPLUNC1 belonging to innate immune molecules, is a secreted protein with specific expression in the respiratory mucosa and is one of the key proteins involved in the host defense in the respiratory tract. Therefore, SPLUNC1 plays a significant role in maintaining normal physiological activities of the upper respiratory tract, inflammatory inhibition, sterilization and tumor suppression. Our previous studies found that SPLUNC1 removes and inhibits gram-negative bacteria proliferation (37), and also plays an important role in resisting EBV infection $(38,39)$. By assessing the levels in clinical specimens, we observed that SPLUNC1 expression in nasopharyngeal epithelial tissues was weaker than that in normal nasopharyngeal epithelial tissues, while TLR9 expression exhibited a contrasting trend. The phenomenon was found mostly consistent with the two expression in corresponding cells. Meanwhile, the expression of TLR9 and SPLUNC1 exhibited an increasing trend following EBV infection in the HNE2 cells. We considered that the increase in SPLUNC1 in the tumor-inflammatory microenvironment was not sufficient enough to inhibit the inflammatory responses mediated by TLR9. In addition, SPLUNC1 had low expression in HNE2 cells. This phenomenon was found not only in EBV cell-tocell transferred infection of HNE2 cells, but also in EBV-DNA direct transfection of HNE2 cells. Therefore, after EBV-DNA direct transfer, inflammatory cytokine expression of TLR 9, IL-6, IL-8, IL-1 $\beta$ and TNF- $\alpha$ was weaker in the NP69 cells with higher SPLUNC1 expression than these levels in the HNE2 cells with lower SPLUNC1 expression. The results suggest that SPLUNC1 had a protective effect on the natural resistance to inflammatory reaction in the tumor-inflammatory microenvironment induced by EBV infection and both SPLUNC1 and TLR9 are involved in the tumorigenesis of NPC.

Zhou et al (38) demonstrated that after SPLUNC1 treatment, defects appeared in EBV particle capsid; EBV-infected lymphocytes were interfered by SPLUNC1 and demonstrated apoptosis. SPLUNC1 promoted the cell lysis and apoptosis of B95-8 cells which can produce EBV. Chen et al (39) showed that SPLUNC1 inhibits EBV from transferring into peripheral blood lymphocyte which were pretreated with SPLUNC1 protein, and reduced EBV-related gene expression of EBER, BZLF1 and LMP1 after EBV integration into cells. In the present study, we found after EBV infection, inflammatory cytokine expression levels of IL-6, IL- 8, IL- $1 \beta$ and TNF- $\alpha$ were significantly lower in the HNE2/SPLUNC1 cell group than those in the HNE2/Vector cell group. The results suggest that SPLUNC1 participates in regulating the inflammatory reaction induced by EBV infection of HNE2 cells. Several studies have indicated that SPLUNC1 exhibited a host defense function through interaction with TLRs. Chu et al (40) reported that airway epithelial TLR2 signaling was pivotal in mycoplasma-induced SPLUNC1 production. When the TLR2 signaling pathway was treated with RNAi of Pam3CSK4 
which is a TLR-2 ligand, SPLUNC1 expression in normal human bronchial epithelial cells was obviously decreased. Thaikoottathil and Chu (41) found that TLR2-mediated MAPK/AP-1 activation upregulated lung epithelial SPLUNC1 expression at the transcriptional level. However, to date, there are rare reports concerning the interaction of SPLUNC1 and TLR9 in the inflammatory response induced by EBV infection of NPC. In the present study, the TLR9 level was significantly lower in the HNE2/SPLUNC1 cell group than that in the HNE2/Vector cell group. Obviously, this indicates that TLR9 plays a certain role in regulating the inflammatory response of SPLUNC1.

In the present study, we found that exogenous SPLUNC1 molecules were transiently transfected to HNE2 cells which had been infected with EBV for $48 \mathrm{~h}$. They could obviously promote $\mathrm{NF}-\kappa \mathrm{B}$ inhibitor IK $\beta \alpha$, reduce TLR9/NF- $\kappa \mathrm{B}$ pathwayassociated cytokine expression (TLR9, CD14, MyD88, IKK, $\mathrm{P}-\mathrm{IK} \beta \alpha, \mathrm{P}-\mathrm{NF}-\kappa \mathrm{B}$ and NF- $\kappa \mathrm{B}$ ) which was induced by EBV infection of HNE2 cells, and consequently increase inflammatory cytokine expression of IL- 6 , IL- 8 , IL- $1 \beta$ and TNF- $\alpha$. Meanwhile, we investigated endogenous SPLUNC1 regulatory effect on EBV infection in HNE2/SPLUNC1 stably transfected cell lines. The results showed that the expression levels of the TLR9/NF- $\kappa \mathrm{B}$ pathway-associated cytokines were greatly decreased after EBV infection of HNE2/SPLUNC1 cells, and on the contrary the expression of $N F-\kappa B$ inhibitor IK $\beta \alpha$ had a conflicting pattern, which was similar to transient transfection above. Regardless of the transfection type, the inflammation cytokine expression levels of IL-6, IL-8, IL-1 $\beta$ and TNF- $\alpha$ in the HNE2/SPLUNC1 cell group were markedly lower than these levels in the HNE2/Vector cell group. These results suggest that SPLUNC1 plays a significant role in the regulation of the TLR9/NF- $\mathrm{BB}$ signal pathway-mediated inflammatory response induced by EBV infection in NPC.

In conclusion, in the present study, on the basis of two established modes of cell infection, we demonstrated that EBV infection of NPC cells activates the TLR9/NF- $\kappa \mathrm{B}$ signaling pathway, promotes release of inflammatory cytokines and consequently enhances the inflammatory response; SPLUNC1 has the ability to weaken this inflammatory response induced by EBV infection of NPC cells through the regulation of the TLR9/NF- $\kappa \mathrm{B}$ signaling pathway, controlling the tumorinflammatory microenvironment and playing a regulatory role in tumorigenesis. Thereby, the regulatory chain of EBV-SPLUNC1-TLR9/NF- $\mathrm{B}$ inflammation was designed to illustrate the inflammatory regulation mechanism of NPC tumorigenesis and provide an innovative theoretical foundation for potential therapeutic targets for NPC.

\section{Acknowledgements}

This study was supported by grants from the National High Technology Research and Development Program of China (no. 2012AA02A206), the National Natural Science Foundation of China (nos. 91229122, 81071644, 81101509, 81171934, 81172189, 81171930 and 81272298), the 111 Project (no. 111-2-12) and the Hunan Province Natural Sciences Foundation of China (no. 10JJ7003). We thank the GSF-National Research Center for Environment and Health (Germany) and Professor Wolfgang Hammerschmidt for allowing us to use the Maxi-EBV system.

\section{References}

1. Gu AD, Zeng MS and Qian CN: The criteria to confirm the role of Epstein-Barr virus in nasopharyngeal carcinoma initiation. Int J Mol Sci 13: 13737-13747, 2012.

2. Odumade OA, Hogquist KA and Balfour HH Jr: Progress and problems in understanding and managing primary Epstein-Barr virus infections. Clin Microbiol Rev 24: 193-209, 2011.

3. Thompson MP and Kurzrock R: Epstein-Barr virus and cancer. Clin Cancer Res 10: 803-821, 2004.

4. Teramoto N, Gogolák P, Nagy N, Maeda A, Kvarnung K, Björkholm T and Klein E: Epstein-Barr virus-infected B-chronic lymphocyte leukemia cells express the virally encoded nuclear proteins but they do not enter the cell cycle. J Hum Virol 3: 125-136, 2000.

5. Imai S, Nishikawa $\mathbf{J}$ and Takada K: Cell-to-cell contact as an efficient mode of Epstein-Barr virus infection of diverse human epithelial cells. J Virol 72: 4371-4378, 1998.

6. Li QX, Young LS, Niedobitek G, Dawson CW, Birkenbach M, Wang F and Rickinson AB: Epstein-Barr virus infection and replication in a human epithelial cell system. Nature 356: 347-350, 1992.

7. Zhang B, Nie X, Xiao B, Xiang J, Shen S, Gong J, Zhou M, Zhu S, Zhou J, Qian J, et al: Identification of tissue-specific genes in nasopharyngeal epithelial tissue and differentially expressed genes in nasopharyngeal carcinoma by suppression subtractive hybridization and cDNA microarray. Genes Chromosomes Cancer 38: 80-90, 2003.

8. Bingle CD and Craven CJ: Comparative analysis of the PLUNC (palate, lung and nasal epithelium clone) protein families. Biochem Soc Trans 31: 806-809, 2003.

9. Jiang D, Persinger R, Wu Q, Gross A and Chu HW: $\alpha 1$-antitrypsin promotes SPLUNC1-mediated lung defense against Pseudomonas aeruginosa infection in mice. Respir Res 14: 122, 2013.

10. Seshadri S,Lin DC, Rosati M, Carter RG, Norton JE, Suh L, Kato A, Chandra RK, Harris KE, Chu HW, et al: Reduced expression of antimicrobial PLUNC proteins in nasal polyp tissues of patients with chronic rhinosinusitis. Allergy 67: 920-928, 2012.

11. Di YP, Tkach AV, Yanamala N, Stanley S, Gao S, Shurin MR, Kisin ER, Kagan VE and Shvedova A: Dual acute proinflammatory and antifibrotic pulmonary effects of short palate, lung, and nasal epithelium clone-1 after exposure to carbon nanotubes. Am J Respir Cell Mol Biol 49: 759-767, 2013.

12. Lu JH, Tang YL, Yu HB, Zhou JH, Fu CY, Zeng X, Yu ZY, Yin HL, Wu MH, Zhang JY, et al: Epstein-Barr virus facilitates the malignant potential of immortalized epithelial cells: from latent genome to viral production and maintenance. Lab Invest 90: 196-209, 2010.

13. Tsao SW, Wang X, Liu Y, Cheung YC, Feng H, Zheng Z, Wong N, Yuen PW, Lo AK, Wong YC, et al: Establishment of two immortalized nasopharyngeal epithelial cell lines using SV40 large T and HPV16E6/E7 viral oncogenes. Biochim Biophys Acta 1590: $150-158,2002$.

14. Zhou HD, Fan SQ, Zhao J, Huang DH, Zhou M, Liu HY, Zeng ZY, Yang YX, Huang H, Li XL, et al: Tissue distribution of the secretory protein, SPLUNC1, in the human fetus. Histochem Cell Biol 125: 315-324, 2006.

15. Tang YL, Lu JH, Cao L, Wu MH, Peng SP, Zhou HD, Huang C, Yang YX, Zhou YH, Chen Q, et al: Genetic variations of EBV-LMP1 from nasopharyngeal carcinoma biopsies: Potential loss of T cell epitopes. Braz J Med Biol Res 41: 110-116, 2008.

16. Lu J, Tang Y, Zhou M, Wu M, Ouyang J, Gao J, Zhang L, Li D, Chen Q, Xiong W, et al: Gene modification in the genome of Epstein-Barr virus cloned as a bacterial artificial chromosome. Wei Sheng Wu Xue Bao 48: 385-390, 2008 (In Chinese).

17. Chen L, Yin J, Chen Y and Zhong J: Induction of Epstein-Barr virus lytic replication by recombinant adenoviruses expressing the zebra gene with EBV specific promoters. Acta Biochim Biophys Sin (Shanghai) 37: 215-220, 2005.

18. Yu H, Lu J, Zuo L, Yan Q, Yu Z, Li X, Huang J, Zhao L, Tang H, Luo Z, et al: Epstein-Barr virus downregulates microRNA 203 through the oncoprotein latent membrane protein 1: a contribution to increased tumor incidence in epithelial cells. J Virol 86: 3088-3099, 2012.

19. Wang WY, Chien YC, Jan JS, Chueh CM and Lin JC: Consistent sequence variation of Epstein-Barr virus nuclear antigen 1 in primary tumor and peripheral blood cells of patients with nasopharyngeal carcinoma. Clin Cancer Res 8: 2586-2590, 2002.

20. Omerović J, Lev L and Longnecker R: The amino terminus of Epstein-Barr virus glycoprotein $\mathrm{gH}$ is important for fusion with epithelial and B cells. J Virol 79: 12408-12415, 2005. 
21. Karin M: Nuclear factor-kappaB in cancer development and progression. Nature 441: 431-436, 2006.

22. Cavallo F, De Giovanni C, Nanni P, Forni G and Lollini PL: 2011: the immune hallmarks of cancer. Cancer Immunol Immunother 60 319-326, 2011.

23. Oeckinghaus A, Hayden MS and Ghosh S: Crosstalk in NF-кB signaling pathways. Nat Immunol 12: 695-708, 2011.

24. Mantovani A, Allavena P, Sica A and Balkwill F: Cancer-related inflammation. Nature 454: 436-444, 2008.

25. Colotta F, Allavena P, Sica A, Garlanda C and Mantovani A: Cancer-related inflammation, the seventh hallmark of cancer: links to genetic instability. Carcinogenesis 30: 1073-1081, 2009.

26. Takeuchi $\mathrm{O}$ and Akira S: Pattern recognition receptors and inflammation. Cell 140: 805-820, 2010

27. Iwasaki A and Medzhitov R: Regulation of adaptive immunity by the innate immune system. Science 327: 291-295, 2010.

28. Basith S, Manavalan B, Yoo TH, Kim SG and Choi S: Roles of toll-like receptors in cancer: a double-edged sword for defense and offense. Arch Pharm Res 35: 1297-1316, 2012.

29. Amirchaghmaghi E, Taghavi SA, Shapouri F, Saeidi S, Rezaei A and Aflatoonian R: The role of toll like receptors in pregnancy. Int J Fertil Steril 7: 147-154, 2013.

30. Droemann D, Albrecht D, Gerdes J, Ulmer AJ, Branscheid D, Vollmer E, Dalhoff K, Zabel P and Goldmann T: Human lung cancer cells express functionally active Toll-like receptor 9 . Respir Res 6: 1, 2005.

31. Lee JW, Choi JJ, Seo ES, Kim MJ, Kim WY, Choi CH, Kim TJ, Kim BG, Song SY and Bae DS: Increased toll-like receptor 9 expression in cervical neoplasia. Mol Carcinog 46: 941-947, 2007.

32. Berger R, Fiegl H, Goebel G, Obexer P, Ausserlechner M, Doppler W, Hauser-Kronberger C, Reitsamer R, Egle D, Reimer D, et al: Toll-like receptor 9 expression in breast and ovarian cancer is associated with poorly differentiated tumors. Cancer Sci 101: 1059-1066, 2010

33. Ronkainen H,Hirvikoski P, Kauppila S, Vuopala KS, Paavonen TK, Selander KS and Vaarala MH: Absent Toll-like receptor-9 expression predicts poor prognosis in renal cell carcinoma. J Exp Clin Cancer Res 30: 84, 2011.
34. Woods DC, White YA, Dau C and Johnson AL: TLR4 activates $\mathrm{NF}-\kappa \mathrm{B}$ in human ovarian granulosa tumor cells. Biochem Biophys Res Commun 409: 675-680, 2011.

35. Ben Abdelwahed R, Cosette J, Donnou S, Crozet L, Ouakrim H, Fridman WH, Sautès-Fridman C, Mahjoub A and Fisson S: Lymphoma B-cell responsiveness to CpG-DNA depends on the tumor microenvironment. J Exp Clin Cancer Res 32: 18, 2013.

36. Baumann CL, Aspalter IM, Sharif O, Pichlmair A, Blüml S, Grebien F, Bruckner M, Pasierbek P, Aumayr K, Planyavsky M, et al: CD14 is a coreceptor of Toll-like receptors 7 and 9. J Exp Med 207: 2689-2701, 2010.

37. Zhou HD, Li GY, Yang YX, Li XL, Sheng SR, Zhang WL and Zhao J: Intracellular co-localization of SPLUNC1 protein with nanobacteria in nasopharyngeal carcinoma epithelia HNE1 cells depended on the bactericidal permeability increasing protein domain. Mol Immunol 43: 1864-1871, 2006.

38. Zhou HD, Li XL, Li GY, Zhou M, Liu HY, Yang YX, Deng T, Ma J and Sheng SR: Effect of SPLUNC1 protein on the Pseudomonas aeruginosa and Epstein-Barr virus. Mol Cell Biochem 309: 191-197, 2008.

39. Chen P, Guo X, Zhou H, Zhang W, Zeng Z, Liao Q, Li X, Xiang B, Yang J, Ma J, et al: SPLUNC1 regulates cell progression and apoptosis through the miR-141-PTEN/p27 pathway, but is hindered by LMP1. PLoS One 8: e56929, 2013.

40. Chu HW, Gally F, Thaikoottathil J, Janssen-Heininger YM, Wu Q, Zhang G, Reisdorph N, Case S, Minor M, Smith S, et al: SPLUNC1 regulation in airway epithelial cells: role of Toll-like receptor 2 signaling. Respir Res 11: 155, 2010.

41. Thaikoottathil J and Chu HW: MAPK/AP-1 activation mediates TLR2 agonist-induced SPLUNC1 expression in human lung epithelial cells. Mol Immunol 49: 415-422, 2011.

42. Zheng Y, Qin Z, Ye Q, Chen P, Wang Z, Yan Q, Luo Z, Liu X, Zhou Y, Xiong W, et al: Lactoferrin suppresses the Epstein-Barr virus-induced inflammatory response by interfering with pattern recognition of TLR2 and TLR9. Lab Invest 94: 1188-1199, 2014. 